\title{
Comparison of Retzius-sparing robot- assisted laparoscopic radical prostatectomy vs standard robot-assisted radical prostatectomy: a meta-analysis
}

Yu-Li Jiang ${ }^{1,2}$, Gao-Feng Zheng ${ }^{1,2}$, Ze-Peng Jiang ${ }^{1,2}$, Zhen-Li $^{1}$, Xie-Lai Zhou' ${ }^{1}$, Jin Zhou' ${ }^{1}$, Chun-Hua Ye ${ }^{1}$ and Kang-Er Wang ${ }^{1 *}$

\begin{abstract}
Background: To compare the postoperative continence and clinical outcomes of Retzius-sparing robot-assisted laparoscopic radical prostatectomy (RS-RALP) with non-RS RALP for patients with prostate cancer.

Methods: We searched PUBMED, EMBASE and the Cochrane Central Register from 1999 to 2019 for studies comparing RS-RALP to non-RS RALP for the treatment of prostate cancer. We used RevMan 5.2 to pool the data.

Results: A total of eight studies involving 1620 patients were included in our meta-analysis. No significant difference was found in positive surgical margins (PSM), bilateral nerve-sparing, postoperative hernia, complications, blood loss, or operative time. Postoperative continence was better with RS-RALP compared with non-RS RALP (OR=1.02, OR: $2.86,95 \% \mathrm{Cl} 1.94-4.20, p<0.05)$.
\end{abstract}

Conclusions: RS-RALP had a better recovery of postoperative continence than non-RS RALP. The perioperative outcomes were comparable for the two methods.

Keywords: Prostate cancer, Retzius space, Robot-assisted radical prostatectomy, Urinary continence, Meta-analysis

\section{Background}

Robotic-assisted laparoscopic radical prostatectomy (RALP) has been widely used in recent times [1]. The main limitations of RALP involve the preservation of urinary continence and sexual potency and the achievement of comparable oncological outcomes (e.g., avoidance of biochemical recurrence, 5-year overall survival, and 5-year recurrence free survival) [2]. The postoperative quality of life influenced by continence, which is one of the worst complications after radical prostatectomy [3]. Several hypotheses

\footnotetext{
*Correspondence: wangkangerhz@126.com

1 Department of Urology, The Affiliated Hospital of Hang Zhou Normal University, Hangzhou 310015, China

Full list of author information is available at the end of the article
}

have been proposed to explore post-RALP incontinence. The weakening of the puboperinealis from transection, traction injury, or denervation is the most important factor explaining post-RALP urinary incontinence [4]. Galfano et al. first reported that the Retzius space sparing (RS) technique during RALP was efficient in gaining good urinary continence rates while avoiding postoperative complications and yielding no positive surgical margins [5] and also reported better functional and oncological outcomes after treating 200 patients with RS-RALP [6]. RS-RALP preserves the bladder neck and urethral anatomy through a posterior plane to achieve postoperative urinary continence preservation [7]. Lim et al. reported that the RS-RALP technique was superior to 
the non-RS transperitoneal technique in terms of mean console time and postoperative urinary continence rates [8]. Najib et al. performed a similar metaanalysis included four studies comparing the two methods to treat with prosrare cancer [9].

However, the limitations of RS-RALP were the limited working space and its lack of feasibility in a global setting. Abu-Ghanem et al. reported that Retzius space reconstruction after transperitoneal laparoscopic robot-assisted radical prostatectomy was a better way to accelerate postoperative urinary continence, reduce early and postoperative complication rates and shorten LOS [10].

Recently, a meta-analysis conducted by Ficarra et al. indicated that posterior musculofascial reconstruction has the advantage of a one-month urinary continence recovery [11]. Recently, Sayyid et al. reported a review of the advantages of RS-RALP [12]. However, no related review or meta-analysis has addressed these issues. The aim of this systematic review was to evaluate the prevalence of and the risk factors for urinary incontinence and urinary bother, perioperative complications and short-term oncological outcomes with RS-RALP compared to non-RS RALP.

\section{Methods}

\section{Search strategy}

We conducted this meta-analysis according to the Preferred Reporting Items for Systematic Reviews and Meta-Analysis (PRISMA) guidelines (S1). We searched PUBMED, EMBASE and the Cochrane Central Register for studies published in English between 1999 and 2019. We used the following search terms: "Retzius-sparing" OR "Retzius preservation", " robot-assisted radical prostatectomy* and ('Retzius-sparing' OR 'Retzius-space preservation') AND 'robot assisted' AND radical AND prostatectomy". We also used the combined Boolean operators "AND" or "OR" in the title/abstract.

\section{Inclusion and exclusion criteria}

The inclusion criteria were as follows: (1) comparative analysis of RS-RALP with non-RS RALP for the treatment of prostate cancer; (2) studies that reported at least one of the following outcomes: postoperative continence rate, bilateral nerve-sparing rate, console time, blood loss, length of hospital stay, positive surgical margin, postoperative hernia rate, and complication rate; and (3) comparative studies of the two surgical approaches. Two investigators (YLJ and GFZ) reviewed the articles.

The exclusion criteria were as follows: (1) case reports, editorial comments, text not in English, meeting abstracts, reviews and articles without applicable data; (2) studies with insufficient data, such as those that lacked means and standard deviations; and (3) studies that were single-arm trials or were not comparative.

\section{Data extraction}

These two authors extracted data, such as the postoperative continence rate, bilateral nerve-sparing rate, console time, blood loss, length of hospital stay, positive surgical margin, postoperative hernia rate, and complication rate. We recorded the following data: (1) baseline comparative data: study design, study size, body mass index, PSA and Gleason score; (2) intraoperative clinical outcomes: postoperative continence rate, bilateral nerve-sparing rate, console time, blood loss, length of hospital stay, positive surgical margin, postoperative hernia rate, and complication rate; and (3) postoperative complications. Any disagreements were resolved by discussion.

\section{Quality assessment}

We used the New-Ottawa Scale (NOS) to assess the included nonrandomized studies. The NOS scores were evaluated using a 9-point system. An NOS score of 7-9 or above was considered high quality, an NOS score of 4-6 was considered medium quality, and an NOS score of $0-4$ or below was considered low quality. Two reviewers (YLJ and GFZ) assessed the quality of the included studies. Table 1 presents the quality assessments of the included studies.

\section{Statistical analysis}

We used Review Manager Version 5.2 software (The Cochrane Collaboration, Oxford, UK) to perform the analysis of the included data. We used Cochran's $Q$ to evaluate the heterogeneity; if the value of $Q<50 \%$ or $P>0.01$, we believed little heterogeneity was present. However, if $\mathrm{Q}>50 \%$ and $P<0.01$, evident heterogeneity existed. If $\mathrm{I}^{2}>50 \%$, the random effects model was applied. For quantitative data, we used weight mean difference (WMD) or standard mean difference (SMD) to calculate continuous data.

\section{Results}

\section{Literature search}

From the selected databases, our search obtained 99 reports. We removed 31 duplicates. After screening the titles and abstracts, 49 full texts were excluded, of which 1 report was not in English, 1 report was a review, and 5 reports were editorial comments. The remaining 59 reports underwent a comprehensive and detailed evaluation. Ultimately, 8 studies were included in this metaanalysis [8, 10, 13-18]. The process of searching studies is summarized in Fig. 1. Table 2 summarizes the baseline characteristics and assessments of the included studies. 


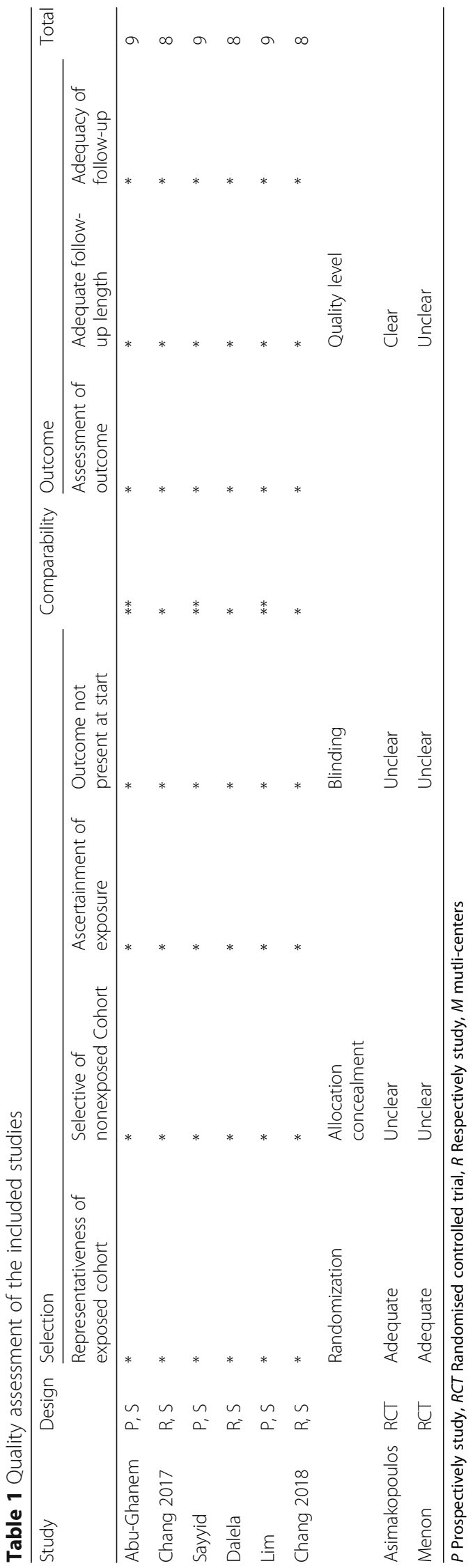




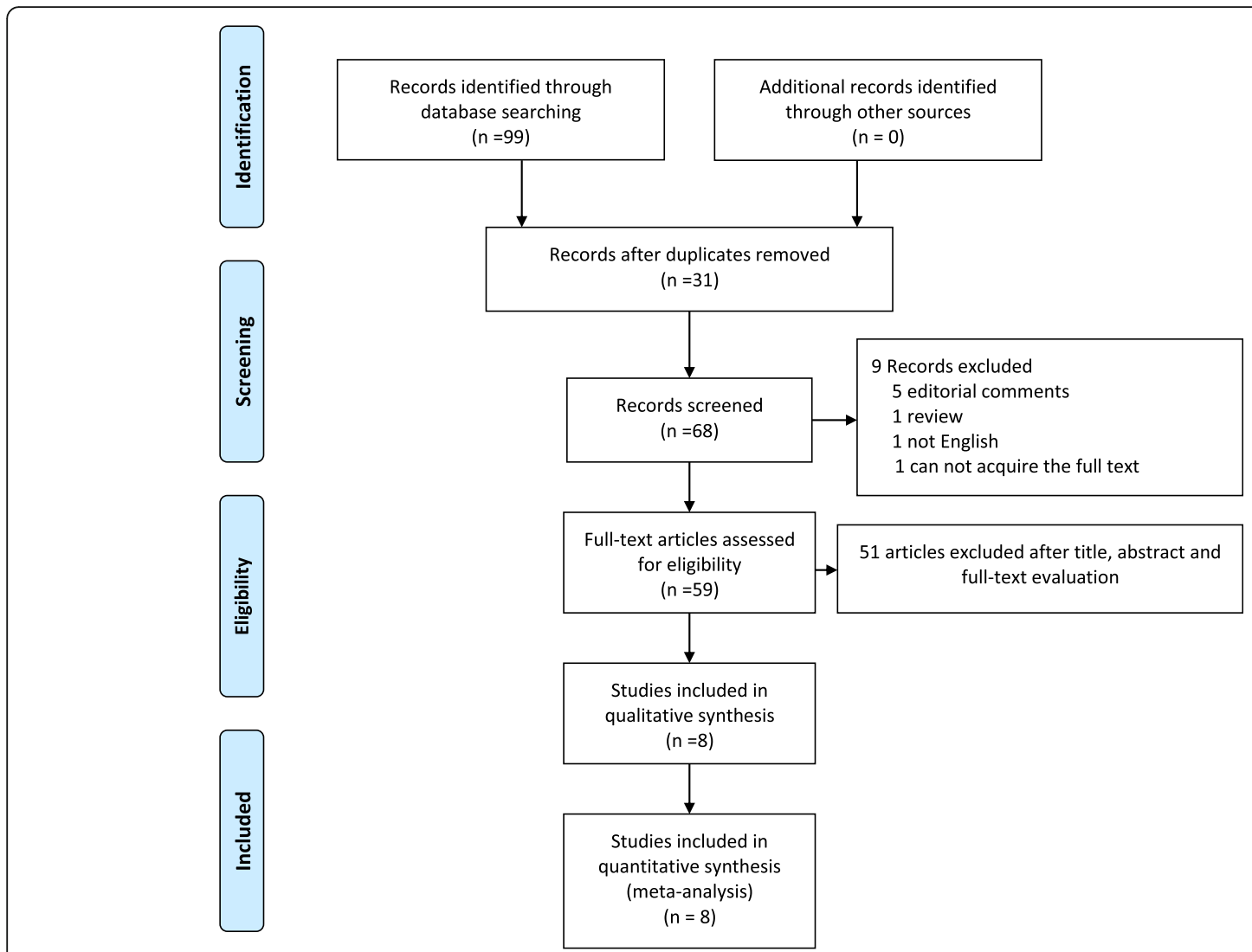

Fig. 1 Flow diagram of the selection process of relevant studies

\section{Continence}

Seven studies reported the postoperative outcome. There was a statistically significant difference between the RS and the non-RS groups ( $n=803$, OR: 2.86 , 95\% CI $1.94-$ $4.20, p<0.05, \mathrm{I}^{2}=0$, fixed-effects model, Fig. 2).

\section{Positive surgical margin}

Data related to positive surgical margins were obtained in four studies. No statistically significant difference between the two groups was noted ( $n=439$, OR: 1.40 , 95\% CI: 0.88 to $2.33, \mathrm{I}^{2}=6 \%$, fixed-effects model, Fig. 3 ).

\section{Bilateral nerve-sparing}

Four studies included in our meta-analysis assessed bilateral nerve-sparing. Bilateral nerve-sparing was comparable between the two groups $(n=459$ patients, OR: 0.98, 95\% CI: 0.48 to $2.01, \mathrm{I}^{2}=56 \%, p=0.96$, randomeffects model, Fig. 4).

Table 2 Basic Characteristics of the Included Studies

\begin{tabular}{|c|c|c|c|c|c|c|c|c|c|c|}
\hline \multirow[t]{2}{*}{ Study } & \multirow[t]{2}{*}{ Year } & \multirow[t]{2}{*}{ Design } & \multicolumn{2}{|c|}{ PSA (ng/dL) } & \multicolumn{2}{|c|}{ prostate volume (ml) } & \multicolumn{2}{|c|}{ Hospital stay } & \multicolumn{2}{|c|}{ Study group } \\
\hline & & & RSS & Non-RS & $\mathrm{RS}$ & Non-RS & $\mathrm{RS}$ & Non-RS & $\mathrm{RS}$ & Non-RS \\
\hline Abu-Ghanem & 2017 & $P, S$ & 9.7 & 7.2 & 61.1 & 62.7 & 4 & 44.9 & 51 & 51 \\
\hline Chang & 2017 & $\mathrm{R}, \mathrm{S}$ & NA & NA & NA & NA & NA & NA & 298 & 541 \\
\hline Sayyid & 2017 & $\mathrm{R}, \mathrm{S}$ & 8.75 & 7.07 & NA & NA & NA & NA & 100 & 100 \\
\hline Dalela & 2017 & $R, S$ & 5.7 & 5.4 & NA & NA & NA & NA & 60 & 60 \\
\hline $\operatorname{Lim}$ & 2014 & $P, S$ & 12.8 & 10.5 & 33.0 & 32.4 & 4.8 & 5.5 & 50 & 50 \\
\hline Chang & 2018 & $R, S$ & 18.24 & 12.2 & 40.11 & 41.33 & NA & NA & 30 & 30 \\
\hline Asimakopoulos & 2018 & $\mathrm{RCT}$ & 7 & 6.9 & NA & NA & NA & NA & 39 & 40 \\
\hline Menon & 2017 & $\mathrm{RCT}$ & NA & NA & NA & NA & NA & NA & 60 & 60 \\
\hline
\end{tabular}

$P$ Prospectively study, $R C T$ Randomised controlled trial, $S$ Single center, $R$ Retrospectively study, $M$ Mutli-centers, NA not avaliable 


\begin{tabular}{|c|c|c|c|c|c|c|c|c|c|}
\hline Studv or Subgroup & $\begin{array}{r}\text { RS } \\
\text { Events }\end{array}$ & 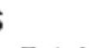 & \multicolumn{2}{|c|}{ non-RS } & Weight & \multirow{2}{*}{$\begin{array}{c}\begin{array}{c}\text { Odds Ratio } \\
\text { M-H, Fixed, 95\% Cl }\end{array} \\
0.65[0.10,4.08]\end{array}$} & \multicolumn{3}{|c|}{$\begin{array}{c}\text { Odds Ratio } \\
\text { M-H, Fixed, } 95 \% \mathrm{Cl}\end{array}$} \\
\hline Abu-Ghanem 2017 & 48 & 51 & 49 & 51 & $9.1 \%$ & & & & \\
\hline Asimakopoulos 2018 & 42 & 45 & 46 & 57 & $8.5 \%$ & $3.35[0.87,12.83]$ & & & \\
\hline Chang 2018 & 22 & 30 & 8 & 30 & $6.7 \%$ & $7.56[2.41,23.75]$ & & & \\
\hline Dalela 2017 & 42 & 59 & 29 & 60 & $26.1 \%$ & $2.64[1.24,5.63]$ & & & $\rightarrow$ \\
\hline $\operatorname{Lim} 2014$ & 35 & 50 & 25 & 50 & $23.7 \%$ & $2.33[1.03,5.30]$ & & & $\longrightarrow$ \\
\hline Menon 2017 & 58 & 60 & 54 & 60 & $5.7 \%$ & $3.22[0.62,16.66]$ & & & \\
\hline Sayvid 2017 & 20 & 100 & 8 & 100 & $20.2 \%$ & $2.88[1.20,6.88]$ & & & \\
\hline Total $(95 \% \mathrm{Cl})$ & & 395 & & 408 & $100.0 \%$ & $2.86[1.94,4.20]$ & & & \\
\hline Total events & 267 & & 219 & & & & & & \\
\hline $\begin{array}{l}\text { Heterogeneity: } \text { Chi }^{2}= \\
\text { Test for overall effect: }\end{array}$ & $\begin{array}{l}62, \mathrm{df}=6 \\
=5.34(\mathrm{P}\end{array}$ & $\begin{array}{l}<P=0 . \\
<0.000\end{array}$ & $\begin{array}{l}47) ;\left.\right|^{2}=0 \\
01)\end{array}$ & & & & 0.01 & $\begin{array}{ll}0.1 & 1 \\
\text { vours } & \text { [RS] }\end{array}$ & $\begin{array}{rr}10 & 100 \\
\text { Favours [non-RS] }\end{array}$ \\
\hline
\end{tabular}

\section{Postoperative hernia}

Two studies were included in our meta-analysis to pool the rate of postoperative hernia. No statistically significant difference between the two groups was noted $(n=$ 68, OR: 2.77 , 95\% CI: 0.06 to $136.11, \mathrm{I}^{2}=92 \%$, randomeffects model, Fig. 5).

\section{Complications}

Four studies were included in our meta-analysis to pool the rate of postoperative complications. No statistically significant difference between the two groups was noted $\left(n=501\right.$, OR: $0.94,95 \%$ CI: 0.58 to $1.54, \mathrm{I}^{2}=48 \%$, fixedeffects model, Fig. 6).

\section{Blood loss}

Among the three included studies reporting blood loss, no statistically significant difference between the two groups was noted $(n=262$, WMD: $3.66,95 \%$ CI: -79.81 to $87.12, \mathrm{I}^{2}=79 \%, p=0.93$, random-effects model, Fig. 7).

\section{Operative time}

Data related to the conversion rate were obtained in three studies. No statistically significant difference between the RS and non-RS groups was found ( $n=239$, WMD: $-3.85,95 \% \mathrm{CI}:-30.37$ to $22.68, p=0.78$, random-effects model, Fig. 8).

\section{Discussion}

In our study, we compared the postoperative continence and clinical outcomes of Retzius-sparing RALP (RSRALP) with non-RSS RALP. No significant difference was found in the positive surgical margin (PSM), bilateral nerve-sparing, postoperative hernia, complications, blood loss, and operative time. The postoperative continence was better with RS-RALP than with non-RS RALP $(p<0.05)$.

Our study indicated that patients who underwent RSRALP had a faster recovery of urinary continence than patients who underwent non-RS RALP (OR: 2.86, 95\% CI 1.94-4.20, $p<0.05$, Fig. 2). Similarly, Ficarra et al. performed a meta-analysis of oncological outcomes after robot-assisted radical prostatectomy and found that the one -year urinary recovery continence rate in the RALP group ranged from 84 to $97 \%$ [11]. Additionally, Chang et al. performed a study involving 60 patients (30 with RS-RALP, 30 with non-RS-RALP) and demonstrated that RS-RALP had an advantage in continence recovery

\begin{tabular}{|c|c|c|c|c|c|c|c|}
\hline Studv or Subgroup & $\begin{array}{r}\mathrm{RS} \\
\text { Events }\end{array}$ & Total & $\begin{array}{c}\text { non- } \\
\text { Events }\end{array}$ & Total & Weight & $\begin{array}{c}\text { Odds Ratio } \\
\text { M-H, Fixed, } 95 \% \mathrm{Cl}\end{array}$ & $\begin{array}{c}\text { Odds Ratio } \\
\text { M-H, Fixed, } 95 \% \mathrm{Cl}\end{array}$ \\
\hline Asimakopoulos 2018 & 11 & 39 & 4 & 40 & $9.4 \%$ & $3.54[1.02,12.30]$ & \\
\hline Chang 2018 & 7 & 30 & 8 & 30 & $20.2 \%$ & $0.84[0.26,2.70]$ & \\
\hline $\operatorname{Lim} 2014$ & 7 & 50 & 7 & 50 & $19.9 \%$ & $1.00[0.32,3.09]$ & \\
\hline Sawid 2017 & 27 & 100 & 21 & 100 & $50.6 \%$ & $1.39[0.72,2.67]$ & \\
\hline Total $(95 \% \mathrm{Cl})$ & & 219 & & 220 & $100.0 \%$ & $1.40[0.88,2.23]$ & \\
\hline Total events & 52 & & 40 & & & & \\
\hline \multicolumn{7}{|c|}{$\begin{array}{l}\text { Heterogeneity: } C^{2}{ }^{2}=3.21, d f=3(P=0.36) ; I^{2}=6 \% \\
\text { Test for overall effect: } Z=1.43(P=0.15)\end{array}$} & \begin{tabular}{|ccccc}
0.01 & 0.1 & 1 & 10 & 100 \\
& Favours & [RS] & Favours [non-RS]
\end{tabular} \\
\hline
\end{tabular}




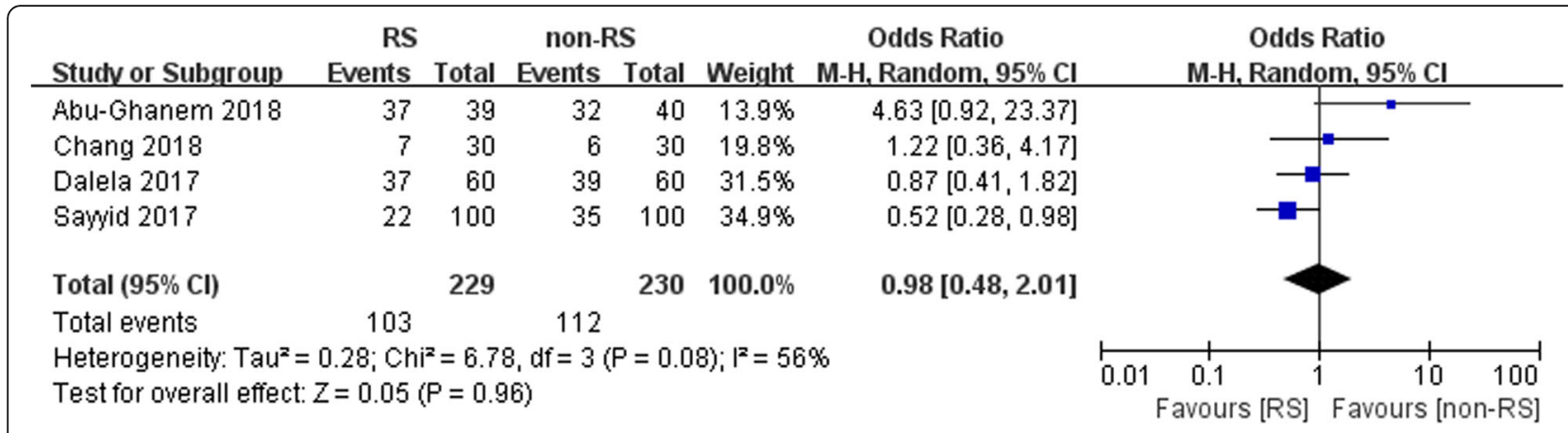

Fig. 4 Forest plot of bilateral nerve-sparing between the two groups

over non-RS-RALP after a multivariate Cox proportional hazard regression analysis (HR: 2.461 95\% CI: $1.362-$ 4.348, $p=0.003$ ) [18]. This is consistent with our results. Galfano et al. reported that the approach allows for the possibility of performing a completely intrafascial operation. During RS-RALP surgery, venosus plexus is not destroyed, thus reducing estimated blood loss [5]. In addition, the complete removal of the pubourethral ligaments is also avoided. Santok et al. conducted a retrospective study of 294 patients with low-grade prostate cancer who underwent RS-RALP. They stratified the patients into three groups according to the different tumor volumes [19]. They found that RS-RALP achieved equivalent oncological and functional outcomes for the three different prostate sizes. No significant difference was found among the three groups $(<40 \mathrm{ml}, 40-60 \mathrm{ml}$, $>60 \mathrm{ml})$ during the 12-month follow-up $(p=0.25)$ [19]. Sayyid et al. conducted a prospective, single-center study comparing RS-RALP with conventional RALP and reported the median time to urinary continence in days (90 vs $160, p<0.001$ ) [16]. This is consistent with our meta-analysis. Ikarashi et al. reported a study that included 204 patients who underwent RALP and suggested that a preoperative membranous urethral length $>12$ $\mathrm{mm}$ (after performing ROC analysis) was an independent predictor of postoperative urinary continence (at the 12-month follow-up) after multivariate analysis ( $p=$ 0.026) [20]. Porpiglia et al. reported a study involving
252 patients and indicated that the continence rate was 98.0\% after catheter removal 24 wk. after RALP. The surgeons performed anterior and posterior constrictions to remodel the natural structures. In the end, the urethral-vesical anastomosis was surrounded by the anterior two layers and posterior three layers of endopelvic fascia, which restored the anatomy and covered the dorsal vascular complex (DVC) and the puboprostatic ligaments [21]. RS-RALP preserves the Retzius space and bladder neck, resulting in postoperative continence during follow-up and a faster attainment of normal urinary function compared to conventional RALP. According to Patel et al., the anterior structures provide anatomical support, allowing for a maximized urethral length for dissection and stabilizing the rhabdosphincter in its anatomical position [22]. Menon et al. performed a similar study involving 2625 patients who received RALP in which no opening of the endopelvic fascia or ligating or suturing of the DVC during the transection of the bladder neck for localized prostate cancer resulted in 95.2\% of the patients being dry after catheter removal [23].

In RS-RALP, the better postoperative recovery of urinary continence was attained by avoiding the destruction of the surrounding urinary structures, thereby providing an ideal urethral length for anastomosis [24].

Lim et al. performed a study that included 50 patients who had at least 6 months of follow-up and prospectively collected patients who underwent RS-RALP and a

\begin{tabular}{|c|c|c|c|c|c|c|c|c|}
\hline Study or Subgroup & $\begin{array}{r}\text { RS } \\
\text { Events }\end{array}$ & \multicolumn{3}{|c|}{ non-RS } & Weight & $\begin{array}{c}\text { Odds Ratio } \\
\text { M-H, Fixed, 95\% Cl }\end{array}$ & \multicolumn{2}{|c|}{$\begin{array}{c}\text { Odds Ratio } \\
\text { M-H, Fixed, } 95 \% \mathrm{Cl}\end{array}$} \\
\hline Abu-Ghanem 2017 & 8 & 51 & 1 & 51 & $2.9 \%$ & $9.30[1.12,77.38]$ & & \\
\hline Chang 2017 & 11 & 298 & 42 & 541 & $97.1 \%$ & $0.46[0.23,0.90]$ & & \\
\hline Total $(95 \% \mathrm{Cl})$ & & 349 & & 592 & $100.0 \%$ & $0.71[0.40,1.25]$ & & \\
\hline Total events & 19 & & 43 & & & & & \\
\hline $\begin{array}{l}\text { Heterogeneity: } \mathrm{Chi}^{2}= \\
\text { Test for overall effect }\end{array}$ & $\begin{array}{l}7.30, d f= \\
Z=1.19(\end{array}$ & $\begin{array}{l}1(P=0 \\
P=0.23\end{array}$ & $\begin{array}{l}0.007) ; 1^{2} \\
\text { 3) }\end{array}$ & $=86 \%$ & & & $\begin{array}{lc}0.01 & 0.1 \\
\text { Favours [RS] }\end{array}$ & 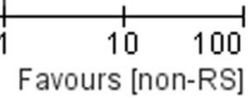 \\
\hline
\end{tabular}




\begin{tabular}{|c|c|c|c|c|c|c|c|}
\hline Studv or Subgroup & $\begin{array}{r}\text { RS } \\
\text { Events }\end{array}$ & Total & $\begin{array}{c}\text { non- } \\
\text { Events }\end{array}$ & Total & Weight & $\begin{array}{c}\text { Odds Ratio } \\
\text { M-H, Fixed, } 95 \% \mathrm{Cl}\end{array}$ & $\begin{array}{c}\text { Odds Ratio } \\
\text { M-H, Fixed, } 95 \% \mathrm{Cl}\end{array}$ \\
\hline Abu-Ghanem 2017 & 9 & 51 & 15 & 51 & $37.6 \%$ & $0.51[0.20,1.31]$ & $\square$ \\
\hline Asimakopoulos 2018 & 1 & 39 & 3 & 40 & $8.8 \%$ & $0.32[0.03,3.26]$ & \\
\hline Lim 2014 & 3 & 50 & 7 & 50 & $20.1 \%$ & $0.39[0.10,1.61]$ & \\
\hline Menon 2017 & 11 & 60 & 7 & 60 & $17.4 \%$ & $1.70[0.61,4.73]$ & \\
\hline Sayid 2017 & 12 & 100 & 6 & 100 & $16.1 \%$ & $2.14[0.77,5.94]$ & \\
\hline Total $(95 \% \mathrm{Cl})$ & & 300 & & 301 & $100.0 \%$ & $0.94[0.58,1.54]$ & \\
\hline Total events & 36 & & 38 & & & & \\
\hline \multicolumn{7}{|c|}{$\begin{array}{l}\text { Heterogeneity: } \text { Chi }^{2}=7.63, \mathrm{df}=4(\mathrm{P}=0.11) ;\left.\right|^{2}=48 \% \\
\text { Test for overall effect: } Z=0.24(P=0.81)\end{array}$} & $\begin{array}{|lcccc|}0.01 & 0.1 & 1 & 10 & 100 \\
& \text { Favours [RS] } & \text { Favours [non-RS] }\end{array}$ \\
\hline
\end{tabular}

propensity score matched conventional group that underwent conventional RALP; they found that the postoperative continence rate was $70 \%$ vs $50 \%$, respectively $(p=0.039)$ [8]. These results are also consistent with our study. They also found that there was no significant difference between the groups of patients in both pT2 and pT3 stages ( $p=0.54$ vs $P=0.95$, respectively) [8].

In the present study, the data regarding positive surgical margins were obtained in four studies and showed no statistically significant difference between the two groups (OR: 1.40, 95\% CI: 0.88 to 2.33, Fig. 3). Similarly, Novara et al. conducted a meta-analysis indicating a similar PSM rate (RARP vs retropubic radical prostatectomy (RRP)): OR: $1.21 ; p=0.19)$. They also assessed the continence of the patients in the pT2 stage and suggested that the two groups achieved a comparable PSM rate [25]. In a study by Asimakopoulos et al., 102 consecutive prostate cancer patients were prospectively randomized to TR-RALP (57) or RS-RALP (45). They also found no significant difference between the two groups.

The study by Dalela et al. involved a total of 120 consecutive patients who were assigned to receive RS-RALP. They also found that the overall PSM rate was 13\% for the RS-RALP versus $25 \%$ for the non-RS RALP $(p=0.1)$ [15]. This finding is consistent with our results. However, this study had several limitations. They did not stratify patients according to the NCCN guidelines for clinically high-risk or lower-risk prostate cancer, which increased bias. The results were also influenced by the limited number of patients. Furthermore, they did not control for potential bias. Sayyid et al. reported that the PSM rate was comparable between the two groups.

Our study showed that bilateral nerve-sparing was comparable between the two groups (OR: 0.98, 95\% CI: 0.48 to $2.01, p=0.96$, Fig. 4). Similarly, Sayyid et al. found that bilateral nerve-sparing was not associated with the surgical approach $(p=0.09)$ [16]. Additionally, Galfano et al. also concluded that the postoperative first intercourse was comparable $(p=0.162)$ [6].

In the present study, no statistically significant difference was found in postoperative hernia between the two groups (OR: 2.77, 95\% CI: 0.06 to 136.11, Fig. 5). However, Abu-Ghanem et al. performed a study containing 51 patients who underwent RS-RALP and 51 patients who underwent non-RS RALP and suggested that the $12 \mathrm{~mm}$ port-site hernia rates were $13.7 \%$ vs $2 \%$ in the RS-RALP vs non-RS RALP $(p=0.03)$, respectively. Chang et al. conducted a retrospective study recruiting a total of 839 patients who received RALP (298 in RSRALP vs 541 in C-RALP), demonstrating that the patients with C-RALP had a higher incidence of inguinal hernia than those with RS-RALP (79.2 vs $20.8 \%$, respectively, $P=0.02$ ) [14]. Recently, Qin et al. performed a case-control study in which 110 patients underwent RSRALP and indicated that RS-RALP increased the recovery of urinary continence [26]. However, they found that

\begin{tabular}{|c|c|c|c|c|c|c|c|c|c|}
\hline \multirow[b]{2}{*}{ Studv or Subgroup } & \multicolumn{3}{|c|}{ RS } & \multicolumn{2}{|c|}{ non-RS } & \multirow[b]{2}{*}{ Total } & \multirow[b]{2}{*}{ Weight } & \multirow{2}{*}{$\begin{array}{l}\text { Mean Difference } \\
\text { IV, Random, } 95 \% \mathrm{Cl}\end{array}$} & \multirow{2}{*}{$\begin{array}{c}\text { Mean Difference } \\
\text { IV, Random, } 95 \% \mathrm{Cl}\end{array}$} \\
\hline & Mean & SD & Total & Mean & SD & & & & \\
\hline Abu-Ghanem 2017 & 379 & 30.2 & 51 & 328 & 59 & 51 & $42.7 \%$ & $51.00[32.81,69.19]$ & + \\
\hline Chang 2018 & 149.52 & 108.67 & 30 & 268.33 & 274.96 & 30 & $25.6 \%$ & $-118.81[-224.61,-13.01]$ & \\
\hline $\operatorname{Lim} 2014$ & 299 & 184 & 50 & 260 & 212 & 50 & $31.6 \%$ & $39.00[-38.81,116.81]$ & \\
\hline Total $(95 \% \mathrm{Cl})$ & & & 131 & & & 131 & $100.0 \%$ & $3.66[-79.81,87.12]$ & \\
\hline \multicolumn{9}{|c|}{$\begin{array}{l}\text { Heterogeneity: } \text { Tau}^{2}=4157.87 ; \mathrm{Chi}^{2}=9.64, \mathrm{df}=2(\mathrm{P}=0.008) ; \mathrm{I}^{2}=79 \% \\
\text { Test for overall effect: } Z=0.09(\mathrm{P}=0.93)\end{array}$} & 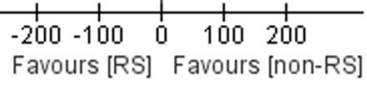 \\
\hline
\end{tabular}

Fig. 7 Forest plot of blood loss between the two groups 


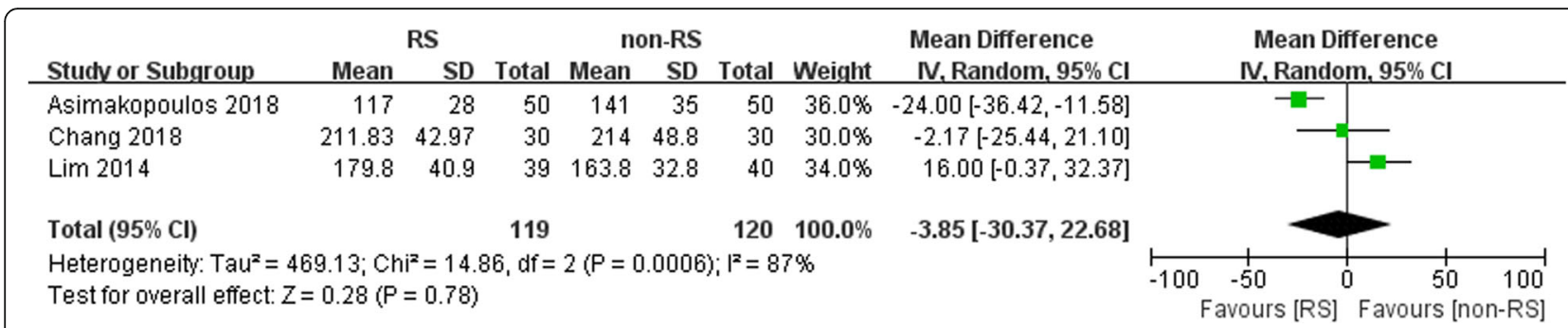

Fig. 8 Forest plot of operative time between the two groups

prostate volume was an independent factor that impacted urinary continence after a multivariable regression analysis $(p=0.032)$.

Additionally, preservation of the anatomical structures of the anterior compartment, i.e., the retropubic (Retzius) space, may preserve the myopectineal orifice and its components, thereby avoiding the medial movement of the internal ring, unlike what occurs with the C-RALP technique $[6,8,27]$. They believe that the preservation of urethral support and of the anterior anatomical structures during RS-RALP resulted in a lower incidence of inguinal hernia. However, several studies reported that prostatectomy did not seem to increase the incidence of inguinal hernia after RRP. Nielson et al. and Lodding et al. reported that the retraction or stretching of the transversalis fascia or vas deferens can change the natural endopelvic fascia structure of the internal inguinal ring. This may increase the occurrence of postoperative inguinal hernia $[28,29]$. Chang et al. also concluded that the postoperative incidence of inguinal hernia after radical prostatectomy is $1.8-19.4 \%$ [14]. This was consistent with our study. The different duration of postoperative follow-up could make a difference in the occurrence of inguinal hernia. However, the authors stated that 3 years were an independent factor for the occurrence of inguinal hernia.

In the present study, no statistically significant difference between the two groups was noted in terms of the complication rate (OR: 0.94, 95\% CI: 0.58 to 1.54). Similarly, several studies have also reported similar results $[8$, $10,17]$. Postoperative urinary leakage was $11.8 \%$ vs $7.8 \%$, $(p=0.5)$ [10]. However, Sayyid et al. also found that intraoperative complications were higher with RS-RALP $(2 \%)$ vs non-RS RALP $(1 \%)(p=0.56)$. The RS-RALP procedure is unfamiliar to most urologists [16], which can result in the difference between the two groups.

In our present study, no statistically significant difference existed in blood loss between the two procedures (WMD: 3.66, 95\% CI: -79.81 to 87.12, $p=0.93$, Fig. 7). Lim et al. also found that blood loss was comparable between the two groups $(p=0.587)$ [8]. Abu-Ghanem et al. also found that the patients in the RS-RALP group compared with non-RS-RALP: $328 \pm 59$ vs $379 \pm 30.2 \mathrm{ml}$, respectively, $(p=0.4)$. This is partly due to not touching the DVC and avoiding the venous plexus [10].

Our study also found no significant difference in operative time between the RS and non-RS groups (WMD: $-3.85,95 \%$ CI: -30.37 to $22.68, p=0.78$, Fig. 8 ). Sayyid et al. reported a similar outcome. They found that the median console time in minutes (IQR) of the RS and non-RS groups was $(120.0 \quad(105.0-142.0)$ vs 144.0 (118.0-171.0), respectively, $p<0.001$ ) [29].

Our study had several limitations. First, the included studies were not RCTs. This can lower the confidence in our findings. Second, the surgeons worked in highvolume centers, which may not be representative of most urologists. Additionally, the included studies did not report postoperative oncological outcomes and did not have adequate follow-up. The limited included studies permitted pooling of the 5 -year overall survival or recurrence-free survival. Third, the postoperative erectile function was not assessed because of the absence of mean and standard deviation values. We did not perform a cumulative analysis in our study. We did not adjust for the lack of information concerning clinical stage or biopsy parameters. The different prostate cancers and surgical procedures were independent factors determining postoperative continence and the oncological outcomes. The postoperative continence is time to event data. Due to the lack of data on the hazard ratio (HR) and standard error (SE), we could not pool the continence data into $\operatorname{logHR}$ and SE. This could also increase the bias. Additionally, the heterogeneity in our study could not be eliminated, and we could not perform subgroup analyses and meta-regression analyses to explore the potential heterogeneity.

\section{Conclusions}

Our study found that RS-RALP provided a better recovery of postoperative continence than non-RS RALP. The perioperative outcomes were comparable for the two groups. More multicenter high-quality RCTs with large sample sizes are needed to verify the postoperative continence and clinical outcomes of Retzius-sparing RALP (RS-RALP) compared with non-RS RALP for patients with prostate cancer. 


\section{Supplementary information}

Supplementary information accompanies this paper at https://doi.org/10. 1186/s12894-020-00685-4.

\section{Additional file 1: S1 Table. PRISMA check list.}

\section{Abbreviations}

$\mathrm{Cl}$ : Confidence interval; WMD: Weight mean difference; OR: Odds ratio; RS: Retzius-sparing; RRP: Retropubic radical prostatectomy; RALP: Robotassisted laparoscopic radical prostatectomy; PSM: Positive surgical margins

\section{Acknowledgements}

Not applicable.

\section{Authors' contributions}

YLJ and GFZ designed the study. YLJ wrote the manuscript. YLJ, ZPJ, ZL, JZ and XLZ analyzed the data. YLJ, CHY, KEW searched the articles. All authors read and approved the final manuscript.

\section{Funding}

Not applicable.

\section{Availability of data and materials}

All data generated or analyzed during this study are included in this published article.

\section{Ethics approval and consent to participate}

Not applicable.

\section{Consent for publication}

Not applicable.

\section{Competing interests}

The authors declare that they have no competing interests.

\section{Author details}

'Department of Urology, The Affiliated Hospital of Hang Zhou Normal University, Hangzhou 310015, China. ${ }^{2}$ School of Medicine, Hang Zhou Normal University, Hangzhou 310016, China.

\section{Received: 25 April 2019 Accepted: 27 July 2020}

Published online: 03 August 2020

\section{References}

1. Hu JC, Wang Q, Pashos CL, Lipsitz SR, Keating NL. Utilization and outcomes of minimally invasive radical prostatectomy. J Clin Oncol. 2008;26:2278-84.

2. Patel VR, Abdul-Muhsin HM, Schatloff $\mathrm{O}$, Coelho RF, Valero R, Ko YH, et al. Critical review of 'pentafecta' outcomes after robot-assisted laparoscopic prostatectomy in high-volume centres. BJU Int. 2011;108:1007-17.

3. Cambio AJ, Evans CP. Minimising postoperative incontinence following radical prostatectomy: considerations and evidence. Eur Urol. 2006;50:90313 discussion 13

4. Myers RP, Cahill DR, Kay PA, Camp JJ, Devine RM, King BF, et al. Puboperineales: muscular boundaries of the male urogenital hiatus in 3D from magnetic resonance imaging. J Urol. 2000;164:1412-5.

5. Galfano A, Ascione A, Grimaldi S, Petralia G, Strada E, Bocciardi AM. A new anatomic approach for robot-assisted laparoscopic prostatectomy: a feasibility study for completely intrafascial surgery. Eur Urol. 2010:58:457-61.

6. Galfano A, Di Trapani D, Sozzi F, Strada E, Petralia G, Bramerio M, et al. Beyond the learning curve of the Retzius-sparing approach for robotassisted laparoscopic radical prostatectomy: oncologic and functional results of the first 200 patients with $>/=1$ year of follow-up. Eur Urol. 2013:64:974-80

7. Freire MP, Weinberg AC, Lei Y, Soukup JR, Lipsitz SR, Prasad SM, et al. Anatomic bladder neck preservation during robotic-assisted laparoscopic radical prostatectomy: description of technique and outcomes. Eur Urol. 2009:56:972-80.

8. Lim SK, Kim KH, Shin TY, Han WK, Chung BH, Hong SJ, et al. Retzius-sparing robot-assisted laparoscopic radical prostatectomy: combining the best of retropubic and perineal approaches. BJU Int. 2014;114:236-44.
9. Dirie NI, Pokhrel G, Guan W, Mumin MA, Yang J, Masau JF, et al. Is Retziussparing robot-assisted radical prostatectomy associated with better functional and oncological outcomes? Literature review and meta-analysis. Asian J Urol. 2019:6:174-82.

10. Abu-Ghanem Y, Dotan Z, Ramon J, Zilberman DE. Retzius space reconstruction following transperitoneal laparoscopic robot-assisted radical prostatectomy: does it have any added value? J Robot Surg. 2018;12:475-9.

11. Ficarra V, Novara G, Rosen RC, Artibani W, Carroll PR, Costello A, et al. Systematic review and meta-analysis of studies reporting urinary continence recovery after robot-assisted radical prostatectomy. Eur Urol. 2012;62:405-17.

12. Sayyid RK, Madi R. The untold advantages of Retzius-sparing robotic radical prostatectomy. J Endourol. 2018;32:671-2.

13. Menon M, Dalela D, Jamil M, Diaz M, Tallman C, Abdollah F, et al. Functional recovery, oncologic outcomes and postoperative complications after robotassisted radical prostatectomy: an evidence-based analysis comparing the Retzius sparing and standard approaches. J Urol. 2018;199:1210-7.

14. Chang KD, Abdel Raheem A, Santok GDR, Kim LHC, Lum TGH, Lee SH, et al. Anatomical Retzius-space preservation is associated with lower incidence of postoperative inguinal hernia development after robot-assisted radical prostatectomy. Hernia. 2017:21:555-61.

15. Dalela D, Jeong W, Prasad MA, Sood A, Abdollah F, Diaz M, et al. A pragmatic randomized controlled trial examining the impact of the Retziussparing approach on early urinary continence recovery after robot-assisted radical prostatectomy. Eur Urol. 2017;72:677-85.

16. Sayyid RK, Simpson WG, Lu C, Terris MK, Klaassen Z, Madi R. Retzius-sparing robotic-assisted laparoscopic radical prostatectomy: a safe surgical technique with superior continence outcomes. J Endourol. 2017;31:1244-50.

17. Asimakopoulos AD, Topazio L, De Angelis M, Agrò EF, Pastore AL, Fuschi A, et al. Retzius-sparing versus standard robotassisted radical prostatectomy: a prospective randomized comparison on immediate continence rates. Surg Endosc. 2019;33:2187-96.

18. Chang LW, Hung SC, Hu JC, Chiu KY. Retzius-sparing robotic-assisted radical prostatectomy associated with less bladder neck descent and better early continence outcome. Anticancer Res. 2018;38:345-51.

19. Santok GD, Abdel Raheem A, Kim LH, Chang K, Lum TG, Chung BH, et al Perioperative and short-term outcomes of Retzius-sparing robot-assisted laparoscopic radical prostatectomy stratified by gland size. BJU Int. 2017;119:135-41.

20. Ikarashi D, Kato Y, Kanehira M, Takata R, Ito A, Onoda M, et al. Appropriate preoperative membranous urethral length predicts recovery of urinary continence after robot-assisted laparoscopic prostatectomy. World J Surg Oncol. 2018;16:224.

21. Porpiglia F, Bertolo R, Manfredi M, De Luca S, Checcucci E, Morra I, et al. Total anatomical reconstruction during robot-assisted radical prostatectomy: implications on early recovery of urinary continence. Eur Urol. 2016;69:485-95.

22. Patel VR, Coelho RF, Palmer KJ, Rocco B. Periurethral suspension stitch during robot-assisted laparoscopic radical prostatectomy: description of the technique and continence outcomes. Eur Urol. 2009;56:472-8.

23. Menon M, Shrivastava A, Kaul S, Badani KK, Fumo M, Bhandari M, et al. Vattikuti institute prostatectomy: contemporary technique and analysis of results. Eur Urol. 2007:51:648-57 discussion 57-8.

24. Walsh PC. Anatomic radical prostatectomy: evolution of the surgical technique. J Urol. 1998;160:2418-24.

25. Novara G, Ficarra V, Mocellin S, Ahlering TE, Carroll PR, Graefen M, et al. Systematic review and meta-analysis of studies reporting oncologic outcome after robot-assisted radical prostatectomy. Eur Urol. 2012;62:382-404.

26. Qin H, Qiu X, Ma H, Xu L, Xu L, Li X, et al. Predictors for immediate recovery of continence following Retzius-sparing robot-assisted radical prostatectomy: a case-control study. Int Urol Nephrol. 2019;51:825-30.

27. Matsubara A, Yoneda T, Nakamoto T, Maruyama S, Koda S, Goto K, et al. Inguinal hernia after radical perineal prostatectomy: comparison with the retropubic approach. Urology. 2007:70:1152-6.

28. Nielsen ME, Walsh PC. Systematic detection and repair of subclinical inguinal hernias at radical retropubic prostatectomy. Urology. 2005;66:1034-7.

29. Lodding P, Bergdahl C, Nyberg M, Pileblad E, Stranne J, Hugosson J. Inguinal hernia after radical retropubic prostatectomy for prostate cancer: a study of incidence and risk factors in comparison to no operation and lymphadenectomy. J Urol. 2001;166:964-7.

\section{Publisher's Note}

Springer Nature remains neutral with regard to jurisdictional claims in published maps and institutional affiliations. 